\title{
Antitumor effects of an engineered and energized fusion protein consisting of an anti-CD20 scFv fragment and lidamycin
}

\author{
FANG Hong $^{1,3}$, MIAO QingFang ${ }^{1 *}$, ZHANG ShengHua $^{1}$, CHENG Xin $^{2}$, \\ XIONG DongSheng ${ }^{2} \&$ ZHEN YongSu ${ }^{1}$
${ }^{1}$ Institute of Medicinal Biotechnology, Chinese Academy of Medical Sciences and Peking Union Medical College, Beijing 100050, China;
${ }^{2}$ Institute of Hematology \& Hospital of Blood Diseases, Chinese Academy of Medical Sciences and Peking Union Medical College, Tianjin 300020, China; \\ ${ }^{3}$ Cancer Institute \& Hospital, Chinese Academy of Medical Sciences and Peking Union Medical College, Beijing 100021, China
}

Received September 15, 2010; accepted October 26, 2010

\begin{abstract}
Antibody-based fusion proteins are the next generation of antibody therapies for cancer and other diseases. CD20 antigen, which is overexpressed on cell membranes in nearly 95\% of cases of B-cell Non-Hodgkin's Lymphoma, is an attractive target for the therapy of B-lymphoid malignancies. Lidamycin (LDM) is a potent enediyne-containing antitumor antibiotic that now has entered phase II clinical trials. In this study, we prepared an engineered fusion protein, scFv-LDP, consisting of an anti-CD20 scFv fragment and the apoprotein LDP of LDM using DNA recombination. After purification and refolding, scFv-LDP was found to bind specifically to CD20-positive lymphoma cells using ELISA and indirect immunofluorescent cytochemical staining assays. The energized fusion protein scFv-LDP-AE was obtained using molecular reconstitution of the active chromophore AE of LDM and scFv-LDP. MTT assay revealed potent cytotoxicity of scFv-LDP-AE to CD20-positive Raji and Daudi cells, with $\mathrm{IC}_{50}$ values of $1.21 \times 10^{-11}$ and $6.24 \times 10^{-11} \mathrm{~mol} \mathrm{~L}^{-1}$, respectively. An in vivo subcutaneous xenograft model of CD20-positive B cell lymphoma in BALB/c (nu/nu) mice was also utilized. Drugs were given intravenously on day 14 and 21 after tumor transplantation. In terms of maximal tolerated doses, scFv-LDP-AE at $0.3 \mathrm{mg} \mathrm{kg}^{-1}$ suppressed tumor growth by $79.3 \%$, and $\mathrm{LDM}$ at $0.05 \mathrm{mg} \mathrm{kg}^{-1}$ by $68.6 \%(P<0.05)$. Results suggested scFv-LDP-AE could be a potential candidate for tumor-targeting therapy.
\end{abstract}

lymphoma, CD20, lidamycin, scFv, energized fusion protein

Citation: Fang H, Miao Q F, Zhang S H, et al. Antitumor effects of an engineered and energized fusion protein consisting of an anti-CD20 scFv fragment and lidamycin. Sci China Life Sci, 2011, 54: 255-262, doi: 10.1007/s11427-011-4143-4

Non-Hodgkin's Lymphoma (NHL) is a group of malignant diseases originating from the lymphatic system [1], and is the fifth most common malignancy in the world. Although conventional chemotherapy and radiotherapy with NHL treatment is effective, these treatment methods may also kill some normal cells because of their low selectivity, leading to obvious side effects. Therefore targeting therapy is becoming more and more important for increasing the effectiveness of cancer treatment. Most NHL originates from B lymphocytes, and $\mathrm{CD} 20$ antigen is overexpressed on the

*Corresponding author (email: qfmiao2004@yahoo.com) surface of over 95\% of NHL cells. CD20 is expressed on pre-B cells, immature B cells, mature B cells, and resting activated $\mathrm{B}$ cells, but is absent from plasma cells, pluripotent stem cells, and other cell types. By contrast, almost no free CD20 is found in serum. Therefore, CD20 is an ideal target antigen for monoclonal antibody therapy in B-cell NHL [2]. The US FDA has approved three monoclonal antibodies against CD20 on lymphoma cells, including Rituximab, Zevalin and Bexxar [3-5]. In fact the worldwide sales of Ribuximab were approximately $\$ 5.6$ billion in 2009 . Recently anti-CD20 antibodies have attracted wide attention because of their new therapeutic uses in a variety of auto- 
immune diseases [6] (e.g. rheumatoid arthritis [7], systemic lupus erythematosus [8,9] and pemphigus [10]). HI47 (IgG3), a murine monoclonal antibody against CD20, was developed by the Institute of Hematology, Chinese Academy of Medical Sciences in 1990, and was used in the present study. This antibody was named CD20+X at the 4th International Conference on Human Leukocyte Differentiation Antigens [11].

A single-chain variable fragment (scFv) is a fusion protein of the variable regions of the heavy $(\mathrm{VH})$ and light chains (VL) in immunoglobulins, connected with a flexible linker peptide usually composed of $\left(\mathrm{Gly}_{4} \mathrm{Ser}\right)_{3}[12]$. With a size of approximately $25 \mathrm{kD}, \mathrm{scFv}$ has many advantages over intact antibodies. scFv has no Fc-receptor binding activation, shows better penetration into solid tumors, has much lower immunogenicity, and can be produced in prokaryotes. These characteristics render $\mathrm{scFv}$ an attractive alternative to intact antibodies as a targeting drug carrier for therapeutic applications.

Lidamycin (LDM), also called C-1027, is produced by a Streptomyces strain isolated from a soil sample collected in China. As a member of the enediyne-containing antitumor antibiotics family, LDM is one of the most potent antitumor macromolecular peptide antibiotics ever reported [13]. In terms of $\mathrm{IC}_{50}$ values, the cytotoxicity of LDM was 10000fold more potent than that of doxorubicin [14,15]. LDM contains an enediyne chromophore (843 Da), responsible for the extremely potent bioactivity, and a noncovalently bound apoprotein LDP (10500 Da), which forms a hydrophobic pocket for protecting the chromophore. The apoprotein and chromophore can be dissociated and reconstituted, and the biological activity of the rebuilt molecule is comparable to that of natural LDM [16-18]. In vivo experiments demonstrated the marked growth inhibition LDM exerted on different transplantable tumors in mice [19-21]. LDM can cause site-specific cleavage of DNA, induce apoptosis in cancer cells, and inhibit tumor metastasis as well as angiogenesis. All of these responses showed that LDM could serve as a promising 'warhead' compound for preparing antibody-based therapeutics [22]. LDM has now entered phase II clinical trials.

In the present study we utilized the properties of LDM, which can be dissociated and reconstituted, to prepare an antibody-based fusion protein, anti-CD20 scFv-LDP-AE. Within this fusion protein, the scFv of antibody HI47 served as a vehicle and LDM as a "warhead". The antitumor effects of scFv-LDP-AE were subsequently studied.

\section{Materials and methods}

\subsection{Materials}

\subsubsection{Plasmids and strains}

Both E. coli $16 \mathrm{C} 9$ and the expression vector pAYZ-scFv carrying the gene for the $\mathrm{scFv}$ (anti-CD20) were separately preserved and constructed in the Institute of Hematology, CAMS \& PUMC (Tianjin, China). The PGEM-T-LDP vector carrying the gene for apoprotein LDP of LDM was constructed in our laboratory. The pMD 18-T vector and E. coli DH5 $\alpha$ were purchased from Takara (Dalian, China) and BioDev-Tech (Beijing, China), respectively.

\subsubsection{Cells}

The B-cell lymphoma line, Raji and Daudi cells, were cultured in RPMI-1640 supplemented with 10\% fetal calf serum at $37^{\circ} \mathrm{C}$ in a humidified $5 \% \mathrm{CO}_{2}$ atmosphere.

\subsubsection{Drugs and reagents}

Restriction endonucleases and T4 DNA ligases were purchased from Takara (Dalian, China); mouse anti-His-Tag antibody were from Novagen (Darmstadt, Germany); FITC-labeled goat anti-mouse IgG was from Zhongshan Golden Bridge Biotechnology (Beijing, China); horseradish peroxidase-conjugated goat anti-mouse IgG and chemiluminescence detection reagent were from Santa Cruz (California, USA); PVDF membranes, Centriplus YM or Ultrafree-MC filter units were from Millipore (USA); Ni-NTA resin affinity chromatography column and Sephadex G-25 column (PD-10) were from Pharmacia (USA); ampicillin, bacto-yeast extract and bacto-tryptone were from Oxoid (Cambridge, UK); bacto-agar was from Difco (Beijing, China); agarose was from Promega (Madison, USA); MTT was from Sigma and low molecular standard protein was from Takara (Dalian, China).

\subsubsection{Animals}

5-6 week-old BALB/c female nude mice (nu/nu), weighing 16-18 g, were obtained from the Vital River Laboratories (Beijing, China).

\subsection{Methods}

\subsubsection{Construction of expression vector $p A-s c f v-l d p$}

The scFv-gene-encoding fragment was cloned by polymerase chain reaction from the pAYZ-scfv plasmid DNA using direct primer $p l\left(5^{\prime}\right.$-CAGCATATGAACGCGTACGCTCAGGTGAAG-3') and reverse primer $p 2$ (5'-CGCGAATTCTGAACCGCCTCCACCTTTGATCTCCACCTTGGT-3'). The obtained scFv PCR products using Nde I, Mlu I and $E c o$ R I sites were cloned into the 18-T vector, yielding plasmid 18T-scfv. The recombinant 18T-scfv was digested with $N d e \mathrm{I} / E c o \mathrm{R}$ I, and the released $760 \mathrm{bp} s c f v$ gene fragment was subcloned into the pGEMT-LDP plasmid and digested with $N d e \mathrm{I} / E c o \mathrm{R}$ I, creating plasmid pGEMT-scfv$l d p$. Then the pGEMT-scfv-ldp vector was digested with Mlu I/Xho I and the released 1100 bp scfv-ldp fragment was ligated to $\mathrm{pAYZ}$, generating recombinant expression plasmid pAYZ-scfv-ldp. The inserted DNA fragment was confirmed using DNA sequencing. 
1.2.2 Expression of fusion protein anti-CD2O scFv-LDP and Western blot analysis

E. coli strain 16C9 transformed with pAYZ-scfv-ldp was cultured in $2 \times \mathrm{YT}$ medium (bacto-yeast extract $10 \mathrm{~g} \mathrm{~L}^{-1}$, bacto-tryptone $16 \mathrm{~g} \mathrm{~L}^{-1}, \mathrm{NaCl} 5 \mathrm{~g} \mathrm{~L}^{-1}$, ampicillin $50 \mu \mathrm{g}$ $\mathrm{mL}^{-1}$ ) at $37^{\circ} \mathrm{C}$ overnight, whereupon the fermentation broth was centrifuged to collect the bacterial cells. The fusion protein $\mathrm{scFv}$-LDP was induced by resuspending the bacteria in AP5 medium (containing $50 \mu \mathrm{g} \mathrm{mL} \mathrm{m}^{-1}$ ampicillin) and incubating, with gentle shaking, for $24 \mathrm{~h}$ at $30^{\circ} \mathrm{C}$. After induction, four fractions, including medium, periplasmic, soluble cytoplasmic and insoluble samples, were obtained for SDS-PAGE analysis and Western blot detection. For Western blotting, PVDF membranes containing transferred proteins were incubated with a 1:2000 dilution of anti-HisTag monoclonal antibody for 4-5 h, and the bound antibody was detected using a 1:1500 dilution of goat anti-mouse IgG antibody conjugated with horseradish peroxidase and powerful chemiluminescence detection reagents.

\subsubsection{Purification and refolding of fusion protein anti- CD20 scFv-LDP}

The bacterial cell pellets were resuspended in binding buffer $\left(5 \mathrm{mmol} \mathrm{L}{ }^{-1}\right.$ immidazole, $0.5 \mathrm{~mol} \mathrm{~L}^{-1} \mathrm{NaCl}$ and $20 \mathrm{mmol} \mathrm{L}^{-1}$ Tris-HCl, pH 7.9), sonicated and the cell lysate centrifuged. This step was then repeated. The resulting pellet was resuspended and incubated in binding buffer containing $6 \mathrm{~mol} \mathrm{~L}^{-1}$ urea for $1 \mathrm{~h}$. Insoluble material was then removed by centrifugation at $16000 \mathrm{~g}$ for $30 \mathrm{~min}$. The supernatant was filtered through a $0.45 \mu \mathrm{m}$ membrane, and then purified by Ni-NTA resin affinity chromatography column. The resulting purified protein was refolded using stepwise dialysis. Specifically, the anti-CD20 scFv-LDP fusion protein was diluted to $5 \mu \mathrm{mol} \mathrm{L}{ }^{-1}$ with binding buffer containing $6 \mathrm{~mol} \mathrm{~L}^{-1}$ urea, and then $\beta$-mercaptoethanol was added to a final concentration of $10 \mathrm{mmol} \mathrm{L}^{-1}$. After incubation at room temperature for $30 \mathrm{~min}$, the sample was dialyzed against refolding buffer (50 mmol L ${ }^{-1}$ Tris- $\mathrm{HCl} \mathrm{pH} 8.0,1 \mathrm{mmol} \mathrm{L}^{-1}$ EDTA, 200 mmol L ${ }^{-1} \mathrm{NaCl}, 6 \mathrm{~mol} \mathrm{~L}{ }^{-1}$ urea) to remove the $\beta$-mercaptoethanol. Dialysis was then subsequently performed against the same buffer with step-wise reduction in the urea concentration $\left(3,2,1,0.5\right.$, and $\left.0 \mathrm{~mol} \mathrm{~L}^{-1}\right)$. At the $1-\mathrm{mol} \mathrm{L}^{-1}$ dialysis, $750 \mu \mathrm{mol} \mathrm{L}{ }^{-1}$ of glutathione and $400 \mu \mathrm{mol} \mathrm{L}{ }^{-1}$ of L-arginine were added to the dialysis buffer. The sample was then dialyzed against PBS solution ( $\mathrm{pH} 7.4$ ). After centrifugation at $10000 \mathrm{~g}$ for $30 \mathrm{~min}$ at $4^{\circ} \mathrm{C}$, the supernatant was collected. The protein was condensed by centrifugation at $12000-14000 \mathrm{~g}$ and the concentration was determined using a BCA protein assay kit from Pierce.

\subsubsection{Enzyme-linked immunosorbent assays (ELISA)}

96-well plates were coated with $0.01 \%$ polylysine $(200 \mu \mathrm{L}$ well ${ }^{-1}$ ) at $4{ }^{\circ} \mathrm{C}$ overnight and then washed with PBS. Raji or
Daudi cells were grown in 96-well plates, washed with PBS and fixed for 15 min with $0.05 \%$ glutaraldehyde/PBS at $4{ }^{\circ} \mathrm{C}$. Plates were then washed with PBS, and nonspecific binding was blocked by incubation with $1 \%$ BSA/PBS at $4{ }^{\circ} \mathrm{C}$ overnight. The wells were emptied and washed, $50 \mu \mathrm{L}_{\text {well }}{ }^{-1}$ of anti-CD20 scFv-LDP was added in two fold serial dilutions at concentrations ranging from 7.50 to $0.06 \mu \mathrm{mol} \mathrm{L} \mathrm{L}^{-1}$ and were allowed to stand for $2 \mathrm{~h}$ at $37^{\circ} \mathrm{C}$. After removing the unbound scFv-LDP, $50 \mu \mathrm{L}$ well ${ }^{-1}$ of 1500 -fold diluted mouse anti-His-Tag mAb was used as a primary antibody. Following incubation and washing, $50 \mu \mathrm{L}$ well ${ }^{-1}$ horseradish peroxidase-conjugated goat anti-mouse $\mathrm{IgG}$, at a dilution of $1: 2000$, was added as a secondary antibody. A total $100 \mu \mathrm{L}$ of $o$-phenylenediamine substrate solution was added as the coloring reagent, and the reaction was terminated after $10 \mathrm{~min}$ by the addition of $50 \mu \mathrm{L}$ of $2 \mathrm{~mol} \mathrm{~L}^{-1} \mathrm{H}_{2} \mathrm{SO}_{4}$. Absorbance was measured at $492 \mathrm{~nm}$ using a microplate reader.

\subsubsection{Indirect immunofluorescent cytochemical staining}

$1 \times 10^{6}$ Raji cells were resuspended in $30 \mu \mathrm{L}$ PBS containing $20 \mu \mathrm{g} \mathrm{scFv}-\mathrm{LDP}$ and incubated at $4^{\circ} \mathrm{C}$ for $1 \mathrm{~h}$. The supernatant was removed by centrifugation at $2000 \mathrm{~g}$ for $10 \mathrm{~min}$ at $4{ }^{\circ} \mathrm{C}$. After being washed with PBS, the cells were resuspended in PBS solution containing 1500-fold diluted anti-His-Tag mAb and incubated at $4^{\circ} \mathrm{C}$ for $1 \mathrm{~h}$. The supernatant was discarded by centrifugation at $2000 \mathrm{~g}$ for $10 \mathrm{~min}$ at $4{ }^{\circ} \mathrm{C}$. The cells were resuspended in $30 \mu \mathrm{L}$ working solution containing FITC-conjugated goat anti-mouse IgG and incubated at $4^{\circ} \mathrm{C}$ for $30 \mathrm{~min}$. The supernatant was removed and the cells were fixed in $4 \%$ polyformaldehyde. The binding of anti-CD20 scFv-LDP to Raji cells was detected by FACS analysis.

\subsubsection{Preparation of energized fusion protein $s c F v-L D P-A E$} $10 \mathrm{mg}$ of LDM with high potent activity was suspended in $5 \mathrm{~mL}$ methanol and whisked for $5 \mathrm{~min}$ at $4^{\circ} \mathrm{C}$. The mixture was then placed at $-20^{\circ} \mathrm{C}$ for $1 \mathrm{~h}$. Hence, active enediyne (AE) in the supernatant of the reaction mixture was obtained by centrifugation at $16000 \mathrm{~g}$ for $20 \mathrm{~min}$ at $4^{\circ} \mathrm{C}$. The above procedure was repeated again to isolate AE completely. To obtain energized fusion protein scFv-LDP-AE, $\mathrm{AE}$ in methanol was added to scFv-LDP/PBS $\left(10 \mathrm{mmol} \mathrm{L}^{-1}\right.$, $\mathrm{pH} 7.0$ ) with the molecular ratio of $5: 1$ and the volume ratio of $1: 50$. The mixture was then placed at room temperature for $12 \mathrm{~h}$. Purified scFv-LDP-AE was finally separated from free AE using a PD-10 column.

\subsubsection{MTT assays}

CD20-positive Raji or Daudi cells were seeded at 10000 cells well ${ }^{-1}$ in 96 -well plates, and incubated at $37^{\circ} \mathrm{C}$ in a humidified $5 \% \mathrm{CO}_{2}$ incubator overnight. Different concentrations of LDM and scFv-LDP-AE were then added and incubated for an additional $72 \mathrm{~h} .50 \mu \mathrm{L}$ of MTT $\left(2 \mathrm{mg} \mathrm{mL}{ }^{-1}\right.$ 
in serum-free RPMI 1640 medium) was added in each well, and incubated for $4 \mathrm{~h}$ at $37^{\circ} \mathrm{C}$. The culture supernatant was removed gently, and $150 \mu \mathrm{L}$ of DMSO was added to each well. After shaking at room temperature for $15 \mathrm{~min}$, the absorbance was determined using a microplate reader at a wavelength of $570 \mathrm{~nm}$. Based on the average absorbance of triplicate wells, survival ratio was calculated according to the following formula:

$$
\text { Survival ratio }=\left(A_{\text {test }}-A_{\text {blank }}\right) /\left(A_{\text {control }}-A_{\text {blank }}\right) \times 100 \% .
$$

\subsubsection{Animal experiments}

Experiments were performed with 5-6 week old female nude mice. At first, they were exposed to total body irradiation (400 rad) to further suppress their residual immune system and facilitate the establishment of xenografts. On the second day, $2 \times 10^{7}$ Raji cells suspended in $0.2 \mathrm{~mL}$ PBS were subcutaneously injected into the right flank of the mice. On day 14 , the tumors reached approximately $100 \mathrm{~mm}^{3}$. Animals were grouped $(n=6)$ and different doses $(0.1,0.2$ and $0.3 \mathrm{mg} \mathrm{kg}^{-1}$ ) of scFv-LDP-AE were administered IV, as was LDM $\left(0.05 \mathrm{mg} \mathrm{kg}^{-1}\right)$ and scFv-LDP $\left(0.3 \mathrm{mg} \mathrm{kg}^{-1}\right)$. Control mice were injected with PBS. On day 21 , the drugs being tested were readministered. Tumor size was measured every 3 days and tumor volumes were calculated with the following formula: $V=0.5 a \times b^{2}$, where $a$ and $b$ are the long and the perpendicular short diameters of the tumor, respectively. The data are presented as mean \pm SD. Tumor growth curves were plotted and the inhibitory rates of tumor growth were calculated according to the tumor volume. Student's $t$-test was used to determine statistically with significant differences. $P<0.05$ was considered significant.

\section{Results}

\subsection{Construction and expression of the anti-CD20 scFv- LDP fusion protein}

In order to create the anti-CD20 scFv-LDP fusion protein, the DNA sequence encoding for the $\mathrm{scFv}$ fragment of $\mathrm{mAb}$ HI47 was genetically fused to the LDP gene, which encodes for the apoprotein of LDM. Fusion occurred when a fiveamino-acid linker (GGGGS) between the C-terminus of $\mathrm{scFv}$ and the N-terminus of LDP was cloned into the Mlu I/ Xho I restriction sites of the pAYZ expression vector, leading to plasmid pAYZ-scfv-ldp (Figure 1A). The scFv-LDP fusion gene was under the control of the phoA promoter and an (His) ${ }_{6}$-Tag was introduced at the C-terminus of the constructs to facilitate the purification via immobilized metal-affinity chromatography. The fusion gene was composed of $1182 \mathrm{bp}$ and encoded for 394 amino acids.

The plasmid vector pAYZ-scfv-ldp was transformed into E. coli 16C9 and the target protein was induced by AP5 culture medium. As shown in the Coomassie Blue-stained gel in Figure 1B, recombinant proteins accumulated in intracellu-
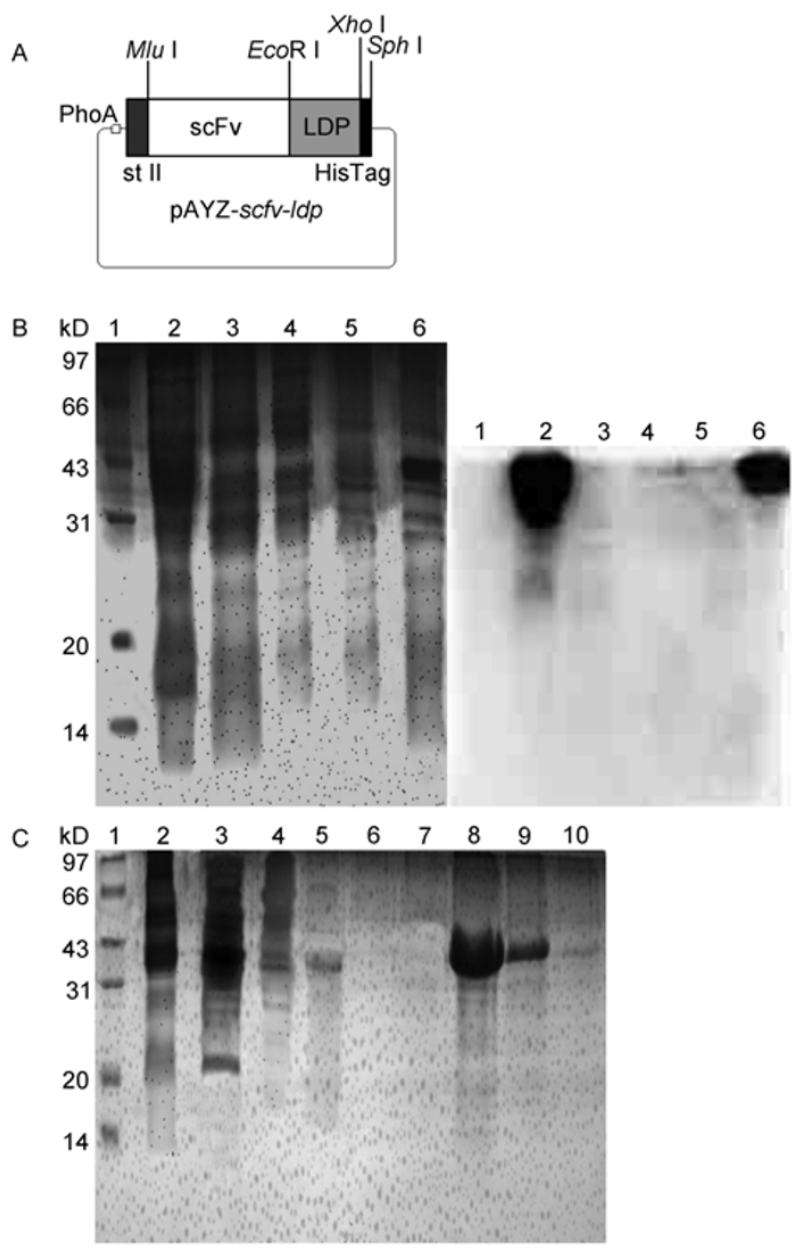

Figure 1 Construction, expression, and purification of the fusion protein, anti-CD20 scFv-LDP. A, Construction of the plasmid pAYZ-scfv-ldp carrying the gene for the fusion protein, scFv-LDP. B, SDS-PAGE (left) and western-blot (right) analysis of each fraction of E. coli $16 \mathrm{C} 9$ cells expressing $\mathrm{scFv}$-LDP fusion proteins. 1: molecular weight marker; 2: total proteins of E. coli 16C9 carrying plasmid pAYZ-scfv-ldp after induction; 3: medium sample; 4: periplasmic fraction; 5: cytoplasmic soluble fraction; 6 : cytoplasmic insoluble fraction. C, Purification of the fusion protein scFvLDP by Ni-NTA affinity chromatography. 1: molecular weight marker; 2 : total cell protein; 3 : sample before $\mathrm{Ni}^{2+}$ column; 4-7: contaminating protein not bound to the resin; $8-10$ : scFv-LDP protein obtained by eluting with stripping buffer.

lar inclusion bodies and composed approximately $30 \%$ of total cell protein. The proteins were running in good agreement with the theoretical molecular weight of $43 \mathrm{kD}$ for the anti-CD20 scFv-LDP fusion protein. The fusion construct was further confirmed by Western blot using an anti-HisTag antibody (Figure 1B).

\subsection{Purification and refolding of the anti-CD20 scFv- LDP fusion protein}

The fusion protein scFv-LDP was purified with Ni-NTA resin under denaturing conditions and target proteins of over 95\% purity were obtained, as shown in Figure 1C. After refolding in a stepwise manner (see Materials and methods), 
$20 \mathrm{mg}$ soluble scFv-LDP could be harvested from $1 \mathrm{~L}$ fermentation broth. The protein was further elucidated using SDS-PAGE, and only a single band with a molecular weight of $43 \mathrm{kD}$ could be discerned, indicating that no degradation or aggregation occurred in the process of purification and refolding.

\subsection{Binding assays}

To confirm the correct folding and functional binding of the fusion protein, the binding ability of anti-CD20 scFv-LDP to CD20-positive tumor cells was examined by ELISA. The data indicated that scFv-LDP bound to the Raji or Daudi cells in a dose-dependent and saturable manner. scFv-LDP interacted with Raji and Daudi cells with relative affinities of $4 \times 10^{-7}$ and $8 \times 10^{-7} \mathrm{~mol} \mathrm{~L}^{-1}$, respectively, which is slightly lower than that of corresponding scFv (Figure 2A and B). Indirect immunofluorescent cytochemical staining and FACS analysis also showed that both scFv and scFv-LDP could specifically bind to Raji or Daudi cells, and the binding activity of $\mathrm{scFv}$ was slightly higher than that of $\mathrm{scFv}$ LDP (Figure 2C). The results indicated that anti-CD20 scFvLDP retained part of the antigen-binding affinity of the parent antibody.

\subsection{Generation of the energized fusion protein anti- CD20 scFv-LDP-AE}

By adding $\mathrm{AE}$, the active enediyne chromophore of LDM, to anti-CD20 scFv-LDP fusion protein solution in controlled conditions, the energized fusion protein scFv-LDP-AE was prepared. scFv-LDP-AE was purified from free AE after separating on a PD-10 column. We found that the scFv-
LDP-AE molecules showed strong absorbance at both 343 and $280 \mathrm{~nm}$, representing the chromophore and protein moiety, respectively (Figure 3).

\subsection{Death of lymphoma cells in vitro due to the ener- gized fusion protein ScFv-LDP-AE}

Cytotoxicity of scFv-LDP-AE and LDM to tumor cells was determined by MTT assay (Figure 4). Both scFv-LDP-AE and LDM displayed extremely potent cytotoxicity to different tumor cells. The $\mathrm{IC}_{50}$ values of scFv-LDP-AE and LDM in CD20-positive Raji cells were $1.21 \times 10^{-11}$ and $7.13 \times$ $10^{-11} \mathrm{~mol} \mathrm{~L}^{-1}$, respectively, and $6.24 \times 10^{-11}$ and $2.91 \times 10^{-10}$ mol L ${ }^{-1}$ in CD20-positive Daudi cells. The $\mathrm{IC}_{50}$ values of scFv-LDP-AE and LDM in CD20-negative MCF7 cells were $3.39 \times 10^{-9}$ and $5.91 \times 10^{-10} \mathrm{~mol} \mathrm{~L}^{-1}$, respectively. The results suggested that the scFv-LDP-AE showed greater cytotoxicity in CD20-positive lymphoma cells than free LDM, which was most likely due to the targeting effects of anti-CD20 scFv in the fusion construct.

\subsection{Animal experiments}

Antitumor experiments were performed with subcutaneous Raji xenografts established in nude mice. As shown in Figure 5, both scFv-LDP-AE and LDM could inhibit or retard the growth of Raji xenografts significantly, with scFv-LDP$\mathrm{AE}$ inhibiting tumor growth in a dose-dependent manner. As evaluated on day 41, scFv-LDP-AE at 0.2 and 0.3 $\mathrm{mg} \mathrm{kg}^{-1}$ suppressed the tumor growth by $70.5 \%$ and $79.3 \%$, respectively, whereas free LDM at the tolerated dose of $0.05 \mathrm{mg} \mathrm{kg}^{-1}$ showed an inhibition rate of $68.6 \%$. The inhibition rate of $\mathrm{scFv}-\mathrm{LDP}-\mathrm{AE}$ at $0.3 \mathrm{mg} \mathrm{kg}{ }^{-1}$ demonstrated

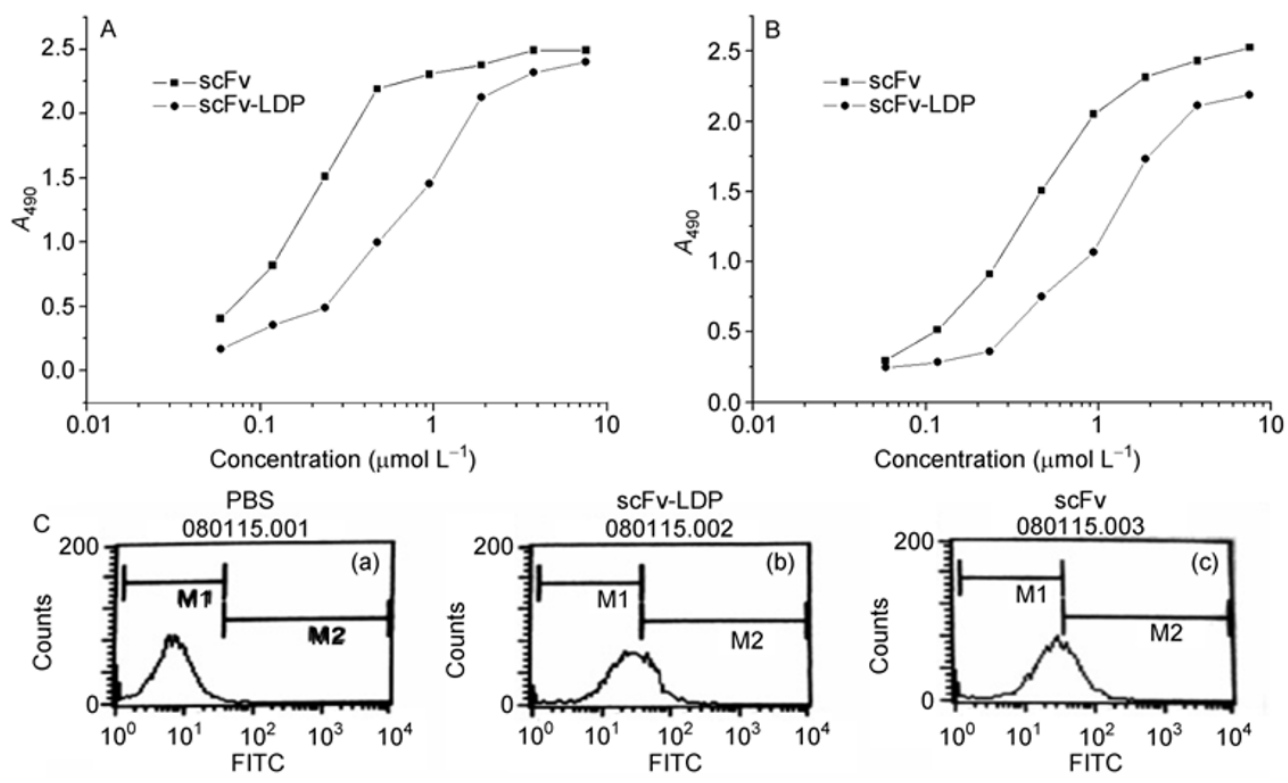

Figure 2 Immunoreactivity analysis of anti-CD20 scFv and scFv-LDP. A, Immunoreactivity to Raji and Daudi cells by ELISA; B, immunoreactivity to Daudi cells by ELISA; C, specific binding to Raji cells by indirect immunofluorescence and FACS analysis. 


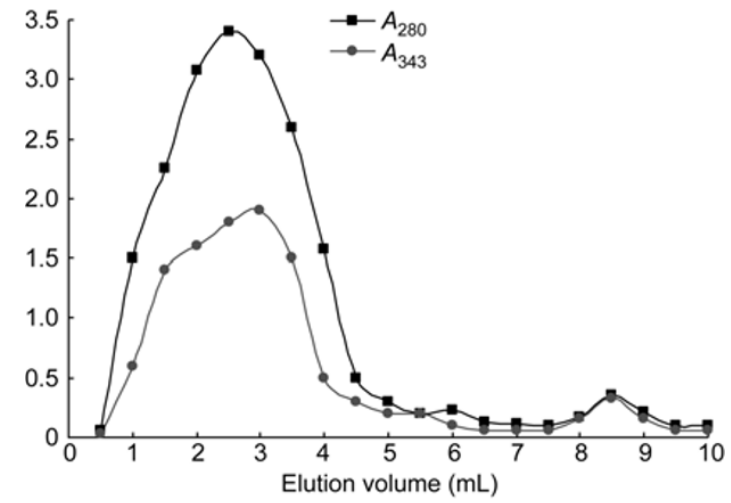

Figure 3 Separation of the energized fusion protein anti-CD20 scFvLDP-AE from free AE on a PD-10 column (Sephadex G-25; Amersham). Elute, $1 \times$ PBS.
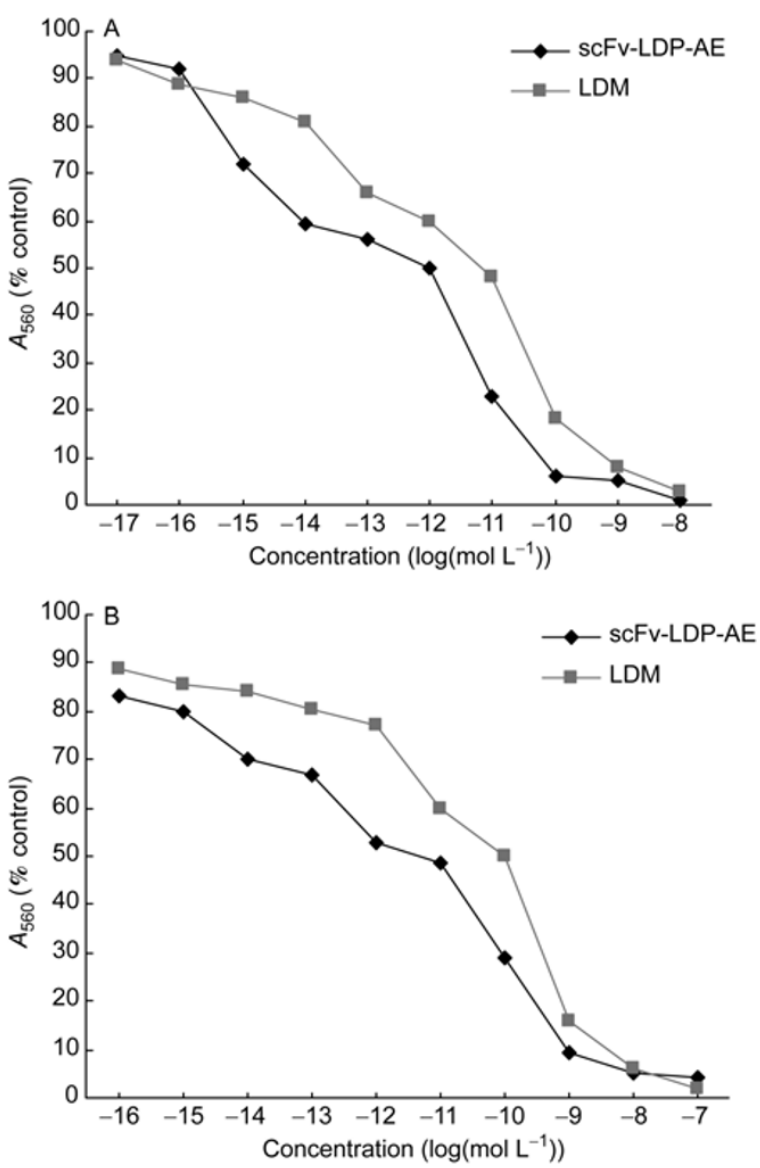

Figure 4 Growth inhibition effects of scFv-LDP-AE and LDM on Raji (A) and Daudi (B) cells determined using MTT assay.

statistically significant differences $(P<0.05)$ compared with that of LDM at $0.05 \mathrm{mg} \mathrm{kg}^{-1}$. Almost no inhibitory effect could be achieved in the group treated with fusion protein scFv-LDP at $0.3 \mathrm{mg} \mathrm{kg}^{-1}$ compared with the control group. All treated mice survived at that time of the study. No severe side-effects were observed during the treatment, which implied that the therapeutic efficacy of scFv-LDP-AE at a tolerated dose was stronger than that of free LDM.

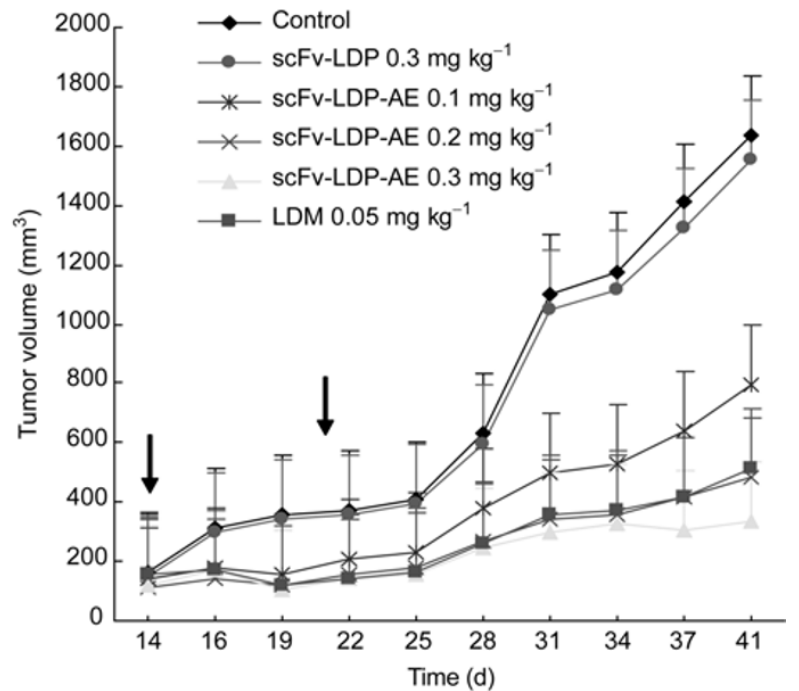

Figure 5 Energized fusion protein scFv-LDP-AE inhibited the growth of Raji xenografts in nude mice.

\section{Discussion}

Since Rituximab (RTX), the CD20-specific chimeric monoclonal antibody, was approved by the US FDA in 1997 for B cell NHL, markedly improved clinical responses in B-lymphoid malignancies have been observed [23]. The success of RTX presents clear opportunity for antibody-based agents in lymphoma therapy. Unfortunately, approximately 50\% of patients with aggressive B-cell NHL are primary refractory or develop relapses after treatment with RTX. The development of Y-90 ibritumomab tiuxetan (Zevalin) and I-131 tositumomab (Bexxar), radiolabelled antibodies with a different mechanism of action compared to RTX, overcame the problem of RTX-resistance. These compounds, however, have their own problems, such as a low response rate following the second treatment, short duration of response, a higher risk for secondary tumors, serious side effects, and poor tolerance in patients $[24,25]$. Therefore, improvements in this area are still greatly required.

Engineered fusion proteins, composed of an antibody fragment and an effector molecule, represent a new class of highly active antibody-based therapeutic that is now being developed for immunotherapy of malignant tumors. In this study we explored a new antibody-targeting fusion protein anti-CD20 scFv-LDP-AE. Anti-CD20 scFv-LDP-AE is composed of an anti-CD20 scFv fragment and LDM. The $\mathrm{scFv}$ moiety plays a crucial role in transferring the LDM to the tumor site, and then LDM kills the tumor cells by causing double strand DNA cleavage $[26,27]$. The fusion construct, therefore, allows the toxic side effects of LDM in normal cells to be avoided. Our results indicate that the engineered and energized fusion protein scFv-LDP-AE not only showed potent cytotoxicity to cancer cells, but also demonstrated significant antitumor effects during in vivo experiments. The fusion protein $\left(0.3 \mathrm{mg} \mathrm{kg}^{-1}\right)$ suppressed 
the growth of Raji xenografts by $79.3 \%$, which demonstrated statistically significant differences $(P<0.05)$ compared with that of LDM at the maximal tolerated doses of $0.05 \mathrm{mg} \mathrm{kg}^{-1}$. This finding suggests that scFv-LDP-AE increases the therapeutic potential of LDM.

scFv-LDP-AE and Rituximab are antibody-based drugs for the same target, CD20, and used in the therapy of B-cell NHL. However, the therapeutic effect of RTX depends on the host immune effector system, including antibody-dependent cell-mediated cytotoxicity (ADCC) and complement-dependent cytotoxicity (CDC). Continuous administration of RTX and high tumor burden can exhaust host effector function and nullify the effect of RTX [28]. The radiolabelled antibodies, Zevalin and Bexxar, exert effects dependent on $\beta$-emissions with path lengths of $1-5 \mathrm{~mm}$, and thus avoid the effector exhaustion problem of RTX. $\gamma$-radiation, however, is a safety concern as they can damage nearby progenitor cells in bone marrow, and cause pancytopenia. Sublethal radiation damage to bone marrow stem cells increases the risk of myelodysplastic syndrome and/or acute myelogenous leukemia. Interestingly, anti-CD20 scFv-LDP-AE elicits cytotoxicity through conjugated LDM without any $\gamma$-radiation, rather than ADCC or CDC effects, and therefore avoids the effector-exhaustion problem, which hampered the efficacy of RTX [29]. In addition, the hypoxic nature of cells within solid tumors limits the efficacy of anticancer therapies, such as ionizing radiation and conventional radiomimetics, because their mechanisms of action require oxygen to induce lethal DNA breaks. Terry et al. [30] reported that LDM could preferentially target hypoxic cells within tumors and overcome the radioresistance associated with poorly oxygenated cells. Therefore, anti-CD20 scFv-LDP-AE has the potential to overcome both the RTX-resistance and the radioresistance associated with poorly oxygenated cells in the treatment of B-cell NHL.

Because the LDM molecule can be separated and reconstituted, we prepared the engineered and energized fusion protein anti-CD20 scFv-LDP-AE consisting of an antiCD20 scFv fragment and LDM using DNA recombination and molecular reconstitution. In contrast to traditional chemical coupling approaches, which lead to heterogeneous products and a complex manufacturing process, our methods preserve the high-order structure and activity of the antibody moiety, and easily obtained the perfect $1: 1$ antibody-effector ratio in the final products. Furthermore, we can obtain the target protein simply in E. coli and avoid the complex and expensive mammalian cell expression systems commonly used for the expression of recombinant antibodies at present time. Therefore, the fusion protein anti-CD20 scFv-LDP-AE could be the next generation of antibodybased drugs offering the potential to overcome RTX-resistance and radioresistance and may be a promising therapy against CD20-positive B-cell lymphoma.
This work was supported by the National High Technology Research and Development Program of China (Grant No. 2006AA02A255), the National Natural Science Foundation of China (Grant No. 30701029), and the National Science and Technology Major Projects (Grant Nos. 2009ZX09103-720 and 2010ZX09401-407).

1 Berinstein N L, Grillo-Lopez A J, White C A, et al. Association of serum Rituximab (IDEC-C2B8) concentration and anti-tumor response in the treatment of recurrent low-grade or follicular non-Hodgkin's lymphoma. Ann Oncol, 1998, 9: 995-1001

2 Van Meerten T, Claessen M J, Hagenbeek A. The CD20/a CD20 'suicide' system: novel vectors with improved safety and expression profiles and efficient elimination of CD20-transgenic T cells. Gene Ther, 2006, 13: 789-797

3 Maloney D G, Smith B, Rose A. Rituximab: mechanism of action and resistance. Semin Oncol, 2002, 29: 2-9

4 Gisselbrecht C. Use of rituximab in diffuse large B-cell lymphoma in the salvage setting. Br J Haematol. 2008, 143: 607-621

5 Bonavida B. Rituximab-induced inhibition of antiapoptotic cell survival pathways: implications in chemo/immunoresistance, rituximab unresponsiveness, prognostic and novel therapeutic interventions. Oncogene, 2007, 26: 3629-3636

6 Polido-Pereira J, Ferreira D, Rodrigues A M. Rituximab use in pediatric autoimmune diseases: four case reports. Ann N Y Acad Sci, 2009, 1173: 712-720

7 Korhonen R, Moilanen E. Anti-CD20 antibody rituximab in the treatment of rheumatoid arthritis. Basic Clin Pharmacol Toxicol, 2010, 106: 13-21

8 Murray E, Perry M. Off-label use of rituximab in systemic lupus erythematosus: a systematic review. Clin Rheumatol, 2010, 29: 707-716

9 Lui N L, Thumboo J, Fong K Y. A case of refractory vasculitic ulcers in a systemic lupus erythematosus patient responding to rituximab and hyperbaric oxygen therapy. Int J Rheum Dis, 2009, 12: 366-369

10 Troiano M, Lotti T. Rituximab in dermatological diseases. G Ital Dermatol Venereol, 2009, 144: 495-499

11 Yang X F, Shen D C, Jin Y G, et al. Preparation and characterization of a monoclonal antibody HI47 direct to human B lymphocyte (in Chinese). Curr Immunol, 1990, 10: 65

12 Harrison J S, Gill A, Hoare M. Stability of a single-chain Fv antibody fragment when exposed to a high shear environment combined with air-liquid interfaces. Biotechnol Bioeng, 1998, 59: 517-519

13 Zhen Y S, Ming X Y, Yu B, et al. A new macromolecular antitumor antibiotic, C-1027. III. Antitumor activity. J Antibiot (Tokyo), 1989, 42: $1294-1298$

14 Shao R G. Pharmacology and therapeutic applications of enediyne antitumor antibiotics. Curr Mol Pharmacol, 2008, 1: 50-60

15 Shao R G, Zhen Y S. Enediyne anticancer antibiotic lidamycin: chemistry, biology and pharmacology. Anticancer Agents Med Chem, 2008, 8: 123-131

16 Zhen Y Z, Lin Y J, Li Y, et al. Lidamycin shows highly potent cytotoxic to myeloma cells and inhibits tumor growth in mice. Acta Pharmacol Sin, 2009, 30: 1025-1032

17 Zhang S H, Chen J, Jiang M, et al. Lidamycin induces apoptosis of human gastric carcinoma BGC823 cells and inhibits xenograft growth in nude mice (in Chinese). Acta Pharma Sin, 2008, 43: 601604

18 Shao R G, Zhen Y S. Relationship between the molecular composition of $\mathrm{C} 1027$, a new macromolecular antibiotic with enediyne chromophore, and its antitumor activity (in Chinese). Acta Pharma Sin, 1995, 30: 336-342

19 Liu X J, Dai Y, Shang Y, et al. Inhibitory effect of lidamycin on growth of colon carcinoma 26 and hepatic metastasis in mice (in Chinese). Ai Zheng, 2005, 24: 641-645

20 Gao R J, Liang Y X, Li D D. Effect of lidamycin on telomerase activity in human hepatoma BEL-7402 cells. Biomed Environ Sci, 2007, 20: 189-197 
21 Huang Y H, Shang B Y, Zhen Y S. Antitumor efficacy of lidamycin on hepatoma and active moiety of its molecule. World J Gastroenterol, 2005, 11: 3980-3984

22 Miao Q F, Liu X Y, Shang B Y, et al. An enediyne-energized single-domain antibody-containing fusion protein shows potent antitumor activity. Anticancer Drugs, 2007, 18: 127-137

23 Fischer L, Penack O, Gentilini C, et al. The anti-lymphoma effect of antibody-mediated immunotherapy is based on an increased degranulation of peripheral blood natural killer (NK) cells. Exp Hematol, 2006, 34: 753-759

24 Van de Loosdrecht A A, Huijgens P C, Ossenkoppele G J. Antibody-targeted therapy: a paradigm of innovative treatment strategies in indolent and aggressive B-cell non-Hodgkin's lymphoma. Curr Opin Hematol, 2004, 11: 419-425

25 Berdeja J G, Hess A, Lucas D M, et al. Systemic interleukin-2 and adoptive transfer of lymphokine-activated killer cells improves antibody-dependent cellular cytotoxicity in patients with relapsed B-cell lymphoma treated with rituximab. Clin Cancer Res, 2007, 13: 2392-2399

26 Xu Y J, Li D D, Zhen Y S. Mode of action of C-1027, a new macromolecular antitumor antibiotic with highly potent cytotoxicity, on human hepatoma BEL-7402 cells. Cancer Chemoth Pharm, 1990, 27: 41-46

27 Sugimoto Y, Otani T, Oie S, et al. Mechanism of action of a new macromolecular antitumor antibiotic, C-1027. J Antibiot (Tokyo), 1990, 43: 417-421

28 Kennedy A D, Beum P V, Solga M D, et al. Rituximab infusion promotes rapid complement depletion and acute CD20 loss in chronic lymphocytic leukemia. J Immunol, 2004, 172: 3280-3288

29 Dillman R O. Infusion reactions associated with the therapeutic use of monoclonal antibodies in the treatment of malignancy. Cancer Metastasis Rev, 1999, 18: 465-471

30 Beerman T A, Gawron L S, Shin S, et al. C-1027, a radiomimetic enediyne anticancer drug, preferentially targets hypoxic cells. Cancer Res, 2009, 69: 593-598

Open Access This article is distributed under the terms of the Creative Commons Attribution License which permits any use, distribution, and reproduction in any medium, provided the original author(s) and source are credited. 